\title{
ARTE E PROPAGANDA IDEOLÓGICA NA REVOLUÇÃO CULTURAL: O EXEMPLO DA OBRA “A MOÇA DO CABELO BRANCO”.
}

\author{
Elizabeth Baptista de Lacerda ${ }^{1}$
}

\begin{abstract}
Resumo: A Grande Revolução Cultural Proletária (1966-1976) surgiu como um recurso para desencadear um movimento de massas que se opusesse ao aparelho partidário, "revisionista" segundo Mao Zedong e seus seguidores, e transformar ideológica e culturalmente a República Popular da China. Nesse contexto, Jiang Qing procurou exercer máxima autoridade sobre as artes representativas, proibindo todas as obras teatrais, chinesas ou ocidentais, exceto aquelas do chamado teatro modelo. O balé "A Moça do Cabelo Branco" foi escolhido para investigar a utilização da adaptação de obras de arte como instrumento de propaganda ideológica, durante a Revolução Cultural. As obras de Jonathan Spence, RoxaneWitke e outras pesquisas acadêmicas permitem comparar o balé com a ópera original, e analisar suas transformações a fim de identificar os objetivos dessas revisões.
\end{abstract}

Palavras Chave: China Contemporânea; Revolução Cultural; Teatro modelo.

Abstract: The Great Proletarian Cultural Revolution (1966-1976) started as a resource to initiate a movement of the masses that could oppose the "revisionist" Party apparatus, according to Mao Zedong and his followers, and could culturally and ideologically transform the People's Republic of China. In this context, Jiang Qing sought to exercise total authority over the representative arts, forbidding all theater plays, whether Chinese or western, except for those of the so-called model theater. The ballet "The White-Haired Girl" was chosen to study the use of the adaptation of works of art as a tool of ideological propaganda during the Cultural Revolution. The works of Jonathan Spence, Roxane Witke and several academic studies permit to compare this ballet to the original work, and analyse its changes in order to identify the goal behind such alterations.

Keywords: Contemporary China; Cultural Revolution; Model Theater.

\section{Introdução}

A ideia de elaboração deste trabalho surgiu ao conhecer a obra de Roxane Witke, "Madame Mao" (1977), resultado de uma série de entrevistas com Jiang Qing, a quarta esposa de Mao Zedong, e uma das líderes da Grande Revolução Cultural Proletária (1966 a 1976), em 1972. Roxane Witke, sinóloga norte-americana, feminista, focava suas pesquisas no tema da mulher chinesa. A autora relata, no primeiro capítulo de seu livro, a forma inesperada como entabulou contato com uma delegação chinesa, em Nova Iorque, em1971, e seu interesse em escrever a história de Jiang Qing desde 1967. O que chamou a atenção nessa obra, a princípio, foi seu ineditismo na época: uma pesquisadora dos Estados Unidos conseguiu entrevistar a mais poderosa líder política

\footnotetext{
${ }^{1}$ Bacharelanda em História na Universidade Federal de Pernambuco. Membro do Grupo de Estudos sobre a História da Ásia do Departamento de História da UFPE. Contato: Rua vitoriano palhares, Torre, 50710190, Recife-PE, Brasil. E-mail: elizabethlacerdagm@ gmail.com.
} 
comunista chinesa. Na verdade, Jiang Qing concedeu os depoimentos com o propósito de que fossem publicados para que sua história fosse conhecida no ocidente.

Jiang Qing era, naquele momento, "malgrado a contida propaganda adversa do governo chinês, a mais poderosa mulher do mundo."2 Tão importante foi esse fato que até hoje "Madame Mao" é referência quando o tema é liderança política feminina, e transformações do papel feminino na China. A trajetória de Jiang Qing, de esposa sempre à sombra do grande Mao, à grande líder da Grande Revolução Cultural Proletária, parece corroborar a afirmativa de Mao Zedong "As mulheres sustentam a metade do céu". Witke observa que "a autonomia que ela conquistou subsequentemente como que comandava outras mulheres à autoridade política, independentemente das relações de seus maridos ou familiares."

Para Mao Zedong, o maior desafio da liderança revolucionária era motivar as massas a abandonarem os antigos valores burgueses e adotarem os interesses da classe proletária. Jiang Qing considerava que "sua verdadeira obra foi a revolução do teatro nacional. Porque no teatro os valores do proletariado poderiam ser corporificados em figuras dramáticas e erigidos, assim, como modelos políticos para todo o povo."4 Dessa forma, foi implacável para denunciar certas obras culturais com elementos burgueses, e decidida a promover a ideologia proletária.

"A Moça do Cabelo Branco", uma narrativa presente no folclore chinês, foi utilizada na forma de ópera na década de 1940, adaptada para o cinema nos anos de 1950, e depois ao balé revolucionário modelo em 1965, quando sofreu mudanças que refletiram os projetos do Partido Comunista da China (PCC) tanto para a produção artística e literária, quanto para mudanças políticas e sociais. Antes de analisar essas alterações ocorridas no balé, faz-se necessária uma abordagem do período em que surgiram as obras do chamado teatro modelo.

Desde a instalação da República Popular da China em 1949, havia divergências dentro da liderança do PCC sobre o melhor tipo de desenvolvimento para o país. O fracasso do Grande Salto Adiante (1958) intensificou essas divergências entre grupos liderados respectivamente por Mao Zedong e Liu Shaoqi. O primeiro, tido como responsável pela catástrofe, afastou-se da chefia do Estado naquele ano, cargo então

\footnotetext{
${ }^{2}$ WITKE, R. Madame Mao. Tradução de Donaldson Garschagen. Rio de Janeiro: Nova Fronteira, 1977, p. 17.

${ }^{3}$ Idem, p. 23.

${ }^{4}$ Idem, p. 270.
} 
assumido por Liu Shaoqi no ano seguinte. Mao Zedong permaneceu, no entanto, como presidente do Partido Comunista e passou a se concentrar no combate ao que considerava 'revisionismo', representado por Liu Shaoqi e outros integrantes dos altos escalões do PCC.

Na década de 1960, Lin Biao agiu dentro do exército para fortalecer a imagem de Mao Zedong como grande líder, organizando "O Livro Vermelho", uma coletânea de citações do Presidente Mao, que foi estudado, inicialmente, por milhões de soldados chineses.

As divergências políticas internas continuavam e o conflito entre as duas linhas partidárias ficaria claro a partir de 1966, quando Mao lançou a Grande Revolução Cultural Proletária. Ela teve suas origens no final de 1965, com uma crítica literária à peça “A destituição de Hai Rui”, escrita pelo vice-prefeito de Xangai, Wu Han. A obra, que versava sobre um funcionário injustamente acusado por um imperador da dinastia Ming, foi interpretada como uma alusão à destituição do Marechal Peng Dehuai, ocorrida em 1959, por ter criticado as medidas implementadas durante o Grande Salto Adiante (1958). No início de 1966, dois grupos de líderes do Partido se reuniram para discutir o caso Wu Han. O primeiro grupo, dirigido por Peng Zhe, prefeito de Pequim, apoiava o statu quo e estava próximo de Liu Shaoqi e Deng Xiaoping. O segundo grupo, em Xangai, sob a orientação de Jiang Qing, constituído por intelectuais radicais, propunha a purificação socialista da arte, e era a favor de novas formas teatrais expurgadas dos valores "feudais" e elitistas ocidentalizados. ${ }^{5}$

\section{O papel de Jiang Qing na Grande Revolução Cultural Proletária}

Jiang Qing, quarta esposa de Mao Zedong, foi atriz de teatro e cinema na década de 1930. Iniciou seus estudos de arte dramática em 1929 no Teatro Experimental de Arte de Jinan, província de Shandong. Em 1931, fundou, com colegas atores, a Sociedade Dramática do Litoral para fazer propaganda antijaponesa nas escolas, fábricas e áreas rurais, numa época de grandes dificuldades oriundas do avanço imperialista nipônico. Nesse período, mulheres jovens organizavam a propaganda, tornando a mensagem política mais inteligível para os camponeses, através de

\footnotetext{
${ }^{5}$ SPENCE, J. D. Em busca da China moderna: quatro séculos de história. Tradução Tomás R. Bueno e Pedro M. Soares. São Paulo: Companhia das Letras, 1995, p. 567.
} 
espetáculos teatrais e de danças, veículos habituais às audiências populares. Esses espetáculos também abordavam personagens femininas de destaque, como a "Mulher de Cabelo Branco". ${ }^{6}$ Qiang Jing adotou então o nome de Lan Ping e atuou em filmes produzidos durante o período da aliança entre as forças comunistas e nacionalistas na Frente Unida Antijaponesa (1937-1945), em que as produções eram utilizadas para a Defesa Nacional.

Chegou, em 1937, em Yan'an, capital das áreas controladas pelo Partido Comunista da China, onde as tropas comunistas se concentraram após a Longa Marcha (1934-1935). Ela foi designada para trabalhar na Academia Lu Xun de Artes e Literatura, onde atuou na área de ensino e direção de teatro. Nessa época, adotou o nome de Jiang Qing. O casamento com Mao Zedong ocorreu em Yan'an e Jiang Qing, que sempre fora atuante politicamente, viu-se excluída dos círculos intelectuais e políticos, pela exigência feita pelo Comitê Central de que ela se mantivesse afastada da vida política. Com reticências, foi aceita a solicitação, em 1937, de divórcio de Mao Zedong de sua terceira esposa, He Zizhen, sua companheira na Longa Marcha.

Jiang Qing tornou-se secretária de Mao Zedong declarando inclusive que nessa função cuidou do Fórum de Yan'an sobre Arte e Literatura (maio1942) que debateu questões sobre a Cultura. Após a fundação da República Popular da China, aos poucos, foi construindo seu próprio lugar dentro da estrutura do Partido. Segundo seu próprio relato para Roxane Witke, na década de 1950, ela viajou pelo interior, sempre incógnita, com nome de Li Chin, por exigência dos membros do Partido, para que não fosse conhecida pelas massas. Essas viagens tinham o propósito de estudar o sistema fundiário, e ela pôde conhecer as dificuldades para a implantação da Reforma Agrária, bem como da Reforma do Casamento, com a resistência dos maridos em relação à concessão do divórcio. Observou que, embora a condição das mulheres chinesas tivesse melhorado, ainda tinham que lutar para que as mudanças estabelecidas pela lei fossem implantadas. ${ }^{7}$

Ao assumir a chefia da censura de cinema na década de 1950, o desafio para Jiang Qing era a realização de muitos filmes, nos padrões defendidos por Mao no Fórum de Yan'an (1942), dirigidos principalmente aos camponeses. Nesse sentido,

\footnotetext{
${ }^{6}$ DABAT, C. R. Mulheres no Movimento Revolucionário chinês (1839-1949). Recife: EDUFPE, 2006, pp. 253-254.

WITKE, R. Madame Mao. Op. cit., p. 226.
} 
censurou várias películas. Entretanto, havia muitas controvérsias quanto ao caráter reacionário ou não das obras, tanto entre os críticos, como entre historiadores e líderes do Partido.

Em 1959, considerou que as peças teatrais encenadas em Xangai, eram claramente burguesas, e anteviu sérios problemas para que a superestrutura ${ }^{8}$ se ajustasse às bases. Convenceu o Presidente Mao da necessidade de recobrar o controle ideológico através da promoção da supremacia proletária nas artes, e começou a retomada do contato com as massas na Campanha da Educação Socialista, iniciada em 1963, em que a ideologia proletária era promovida através de festivais artísticos e educativos, com apoio do Exército Popular de Libertação, chefiado por Lin Biao. ${ }^{9}$ Ao mesmo tempo, Jiang Qing prosseguia com seu trabalho de denunciar as obras teatrais chamadas de "peças fantasmas", que abordavam superstição e crendices, ou peças sobre a sociedade 'feudal' e a burguesia, que não serviam ao socialismo, como, por exemplo, Hai Rui, de Wu Han. Essas e outras obras do gênero eram acusadas de provocar a nostalgia do passado pela idealização das imagens das classes senhoriais e imperiais, enfraquecendo a luta de classes. Poucos líderes comunistas apoiaram Jiang Qing nessa época. ${ }^{10}$

Em 1964, Jiang Qing, a convite de Zhou Enlai, proferiu um discurso no Festival da Ópera de Pequim sobre Temas Contemporâneos, um evento sobre a divulgação das políticas proletárias através do teatro. Nesse discurso, exigia a criação de superestrutura apropriada para "proteger a base econômica do socialismo", e fez um apelo para que o povo fosse representado nos palcos:

O grão que comemos foi plantado pelos camponeses, as roupas que envergamos e as casas em que vivemos foram feitas pelos operários e o Exército Popular de Libertação guarda para nós as frentes de defesa nacional. E nós não falamos deles no palco. Posso perguntar que posição tomam os senhores artistas em matéria de classe? E onde está essa famosa consciência artística de que tanto se fala? ${ }^{11}$

\footnotetext{
${ }^{8}$ Karl Marx e Friedrich Engels recorreram à metáfora do edifício para explicar a sociedade. A sua base ou infraestrutura seria o conjunto das relações de produção, ou seja, as relações de classes estabelecidas em determinada sociedade. Sobre esta estrutura econômica se ergueria a superestrutura, que corresponde às formas de consciência social em geral, como a política, a filosofia, a cultura, as ciências, as religiões, as artes, as visões de mundo e demais componentes ideológicos de uma classe. A superestrutura é derivada do conflito de interesses das diferentes classes de determinada sociedade, e sua função é manter a infraestrutura, reforçando assim os interesses coletivos da classe social dominante. Isto é realizado através da regulamentação, sanções e coerções impostas pela superestrutura política e pela força persuasiva da superestrutura ideológica.

${ }^{9}$ WITKE, R. Madame Mao. Op. cit., p. 259.

${ }^{10}$ Idem, p. 260.

${ }^{11}$ On the revolution of the Peking Opera. Pequim: Foreign Language Press, 1968. Apud WITKE, R. Madame Mao. Op. cit., p. 263.
} 
A Grande Revolução Cultural Proletária, que seguiu acirrando antagonismos dentro da cúpula do PCC, foi provocada por uma luta de sucessão entre Mao Zedong e Liu Shaoqi. Jiang Qing empenhava-se para apoiar Mao Zedong e suas ideias, e também por sua própria sobrevivência política - uma mulher desafiando o domínio masculino, buscando um mandato das massas. Em fevereiro de 1966, ela se uniu a Lin Biao, que comandava o exército, para conquistar uma posição no alto escalão das forças armadas como conselheira para assuntos culturais. Convocou o Fórum sobre o Trabalho de Literatura e Arte das Forças Armadas em Xangai (1966), onde expôs a necessidade da luta de classes, de encorajar a ideologia proletária e eliminar a burguesa. Concomitantemente, Jiang Qing continuou seu trabalho para transformar a consciência profissional de dramaturgos, atores e coreógrafos. ${ }^{12}$

No início desse movimento, a maioria da população tinha menos de 30 anos de idade, e boa parte não havia conhecido a sociedade antes de 1949. A produção cultural estrangeira estava à disposição da população urbana. Mao e Jiang Qing entendiam que as fontes de ideologia burguesa tinham que ser eliminadas, uma vez que a continuidade revolucionária exigia um compromisso das novas gerações, que só poderia ser assegurado pela ideologia que eles defendiam.

Em maio de 1966, o Presidente Mao reorganizou o Grupo Dirigente da Revolução Cultural (GDRC) com líderes leais a ele, entre os quais, Jiang Qing. Em poucos dias, a luta extrapolou do Comitê Central para as universidades e o domínio público. Um cartaz contra a administração conservadora da universidade de Pequim, feito por uma professora, deu início a um clima de violência generalizada. Em agosto e setembro de 1966, houve intensa agitação social, especialmente entre os jovens, convocados a se levantarem para a sucessão revolucionária, a recusarem a autoridade parental e pedagógica. Milhões de jovens se dirigiram para Pequim, e foram recebidos pelo presidente Mao. Estudantes de todo o país, foram incentivados a visitar Beijing, pelo PCC, que lhes ofereceu passagens, refeições e alojamento. Jiang Qing foi ao encontro do povo, angariar apoio para a causa do Presidente, discursando nas grandes concentrações de Guardas Vermelhos.

Em novembro, ocorreu a transferência da Primeira Companhia da Ópera de Pequim, da relativa independência artística e integridade tradicional sob o Comitê Municipal, para submissão à autoridade do Grupo da Revolução Cultural, do qual Jiang

\footnotetext{
${ }^{12}$ WITKE, R. Madame Mao. Op. cit., p. 272.
} 
Qing era vice-líder, e do Exército Popular da Libertação, do qual ela era conselheira cultural. No final de 1966, os meios de comunicação passaram para as mãos dos revolucionários culturais, os jornais foram retirados de circulação ou obrigados a seguir a linha maoísta. No teatro, só se permitia as obras modelo do teatro revolucionário de Jiang Qing. Os estúdios de cinema fecharam, e os roteiristas, produtores, diretores e atores foram humilhados publicamente. Os filmes, com exceção dos então recentemente aprovados pelo Comitê Central, foram banidos. Os atos de Jiang Qing misturavam motivos ideológicos e pessoais. ${ }^{13}$

Para estabelecer uma nova cultura, proletária, os líderes destruíram todos os rivais urbanos e rurais, antigos e modernos, fechando casas de chá, cafés, restaurantes e mercados; recolhendo os artistas de rua tradicionais; suprimindo os festivais religiosos e grandes feriados. Para suprir o interesse pelas artes, Jiang Qing e sua equipe impuseram um repertório modelo de espetáculos dentro da ideologia marxista. O slogan " $a$ destruição deve preceder a construção" foi aplicado às artes representativas, surgindo um repertório de obras-modelo, as yangbanxi, teatro-modelo. Em 1968, haviam sido produzidas oito yangbanxi: quatro óperas ("A Lanterna Vermelha”, "Sha Chiapang", "Estratégia para tomar a Montanha do Tigre", "Ataque ao Regimento do Tigre Branco"); dois balés ("O Destacamento Feminino Vermelho" e "A Moça de Cabelo Branco"); o "Concerto para piano do Rio Amarelo" e uma série de trabalhos de artes plásticas, intitulada "Pátio de coleta de Rendas". ${ }^{14}$

No cinema, as dificuldades foram maiores, não só pela escassez de equipamentos e pessoal técnico, mas também pela destituição de muitos atores, diretores, roteiristas e outros profissionais dessa área, acusados de criarem e atuarem em obras burguesas e revisionistas, o que teria inviabilizado uma produção cinematográfica revolucionária.

Não se pode deixar de comentar que o tradicional teatro chinês já vinha sofrendo alterações desde o final do século XIX, quando foi identificado como uma das causas do atraso da China. Nesse período, os intelectuais organizavam movimentos exigindo reformas e expulsão das potências ocidentais que exploravam o país nas concessões territoriais, e também a remodelação do teatro chinês. ${ }^{15}$ As primeiras iniciativas foram

\footnotetext{
${ }^{13}$ Idem, p. 289.

${ }^{14}$ Idem, pp. 335-336

${ }^{15}$ DING, L. Ershi shiji Zhongguo xiju zhentiguan [Panorama do teatro chinês o século XX.] 2009. Apud SCHMALTZ, M. O moderno teatro chinês: desenvolvimento, percalços e pós-modernidade. Disponível
} 
dos atores da escola clássica, com a introdução de figurinos contemporâneos, argumentos de denúncia, diminuição do canto e da dança, e introdução dos diálogos, coexistindo elementos do tradicional teatro chinês com os do teatro ocidental. Várias obras ocidentais foram traduzidas e encenadas. Nas décadas de 1920 e 1930, certas obras já apresentavam conotação ideológica e eram consideradas instrumentos de propaganda política. ${ }^{16}$

Em 1942, no Fórum de Yan'an, Mao Zedong defendia a necessidade de orientação política em todas as artes:

A nossa reunião de hoje visa converter realmente a literatura e a arte numa parte componente da máquina da revolução, numa arma poderosa para unir e educar o povo, para atacar e destruir o inimigo, e ajudar o povo a combater o inimigo com um mesmo coração e uma mesma vontade. ${ }^{17}$

Jiang Qing acompanhava pessoalmente a produção das peças teatrais e de balé, que eram modificadas várias vezes por meio de debates e comentários que ocorriam nos ensaios abertos ao público. Ela analisava todos os detalhes, revisando a obra, até sua versão final, em que a classe operária sempre era forte, atraente e inteligente. ${ }^{18}$

\section{As obras "A Moça do Cabelo Branco"}

A decisão de Jiang Qing de transformar o balé clássico em revolucionário recebeu oposição dentro do Partido Comunista, mas obteve o apoio de Mao Zedong. Ela optou por usar a fórmula: "Fazer o velho servir ao novo e o estrangeiro ao chinês". Utilizou elementos da ópera chinesa, como canções, acrobacias e expressões faciais, e da cultura local como a música rítmica, a dança e roupas coloridas. ${ }^{19}$

O balé, como as demais obras modelo, segue a orientação marxista-leninista, e maoísta, da eliminação do meio-termo. Os personagens positivos são heróis e só têm qualidades, enquanto que os personagens negativos são bandidos. ${ }^{20}$

em: 〈https://www.researchgate.net/profile/Marcia_Schmaltz/publication/292130117>. Acessado em 10 mai. 2017.

${ }^{16}$ SCHMALTZ, Márcia. O moderno teatro chinês. Op. cit.

${ }^{17} \mathrm{MAO}$, Zedong. "Intervenções no colóquio de Ien-an sobre literatura e arte." In: Obras escolhidas de Mao Tsetung. Tomo III. Disponível em: <https://www.marxists.org/portugues/mao/obras/index.htm> Acessado em 10 maio 2017.

${ }^{18}$ WITKE, R. Madame Mao. Op. cit., p. 351.

${ }^{19}$ Idem, p. 357.

${ }^{20}$ Idem, p. 358. 
O balé "A Moça do Cabelo Branco" se baseou na peça teatral de mesmo nome, produzida em 1945, coletivamente, por um grupo de escritores e artistas do Partido Comunista, após o Fórum de Yan'an para a Arte e Literatura (1942), em que, como mencionado acima, Mao Zedong estabeleceu a política oficial do Partido Comunista Chinês para a arte, criticando severamente correligionários como a grande escritora Ding Ling. A arte deveria ser criada para o povo, um público de trabalhadores, camponeses e soldados, e a cultura deveria ser anti-imperialista e "anti-feudal", "das grandes massas populares, dirigida pelo proletariado." 21

Essa ópera foi inspirada em contos do folclore chinês sobre uma moça com cabelos longos, em várias versões, desde antes do século III. Essas lendas podem ser resumidas como a estória de uma moça que foge para a montanha ou floresta para evitar maus tratos. Ela passa a se alimentar de folhas de pinheiro ou sementes e, por isso, seu cabelo se torna preto, branco, ou verde. Em muitas versões, a moça ainda pode voar. Todas essas estórias refletem o destino das mulheres chinesas no sistema tradicional, sociedade regida pelos princípios confucianos de dependência e obediência em relação ao pai, ao marido e ao filho, onde eram consideradas como propriedade. ${ }^{22}$

Na peça, a heroína Xi'er é filha de um camponês arrendatário, que não consegue pagar seus débitos ao senhorio. Esse rapta a moça e a transforma em escrava, levando o pai ao suicídio. Na casa do senhor de terras, Xi'er sofre maus tratos pelas mulheres da casa, é estuprada pelo latifundiário e engravida. O senhorio planeja assassiná-la, mas Xi'er foge e se esconde nas montanhas, onde dá à luz um filho, que morre de inanição. Sem consumir sal e sem levar sol, ela fica com o cabelo totalmente branco. Os aldeões que a avistam pensam se tratar de um fantasma. Ela é salva pelo Oitavo Exército de Rota ${ }^{23}$ que liberta sua cidade natal. A terra do senhorio é dividida, e Xi'er recebe sua parte.

$\mathrm{Na}$ época, a mensagem da ópera era que a velha sociedade força as pessoas a se tornarem fantasmas, enquanto a nova sociedade devolve a vida aos fantasmas. Durante a

\footnotetext{
${ }^{21}$ MAO, Zedong. "Intervenções no colóquio de Ien-an sobre literatura e arte." In: Obras escolhidas de Mao Tsetung. Tomo III. Op. cit.

${ }^{22}$ JIA, Bo. Gender, Women's Liberation, and the Nation-State: A Study of the Chinese Opera The White-Haired Girl. Disponível em: <https://rucore.libraries.rutgers.edu/rutgers-lib/47419/>. Acessado em 19 dez. 2017.

${ }^{23}$ Designação do Exército Vermelho durante a Frente Unida Anti-Japonesa com o Guomindang (19371946).
} 
Revolução Cultural essa interpretação foi rejeitada por revelar superstição e falta de consciência de classe. ${ }^{24}$

Em 1950, foi lançada a versão em filme, cujo enredo é bem próximo à ópera. É acrescentado o personagem Wang Dachun, noivo de Xi'er que, após o rapto de sua amada, foge, se junta ao $8^{\circ}$ Exército e, posteriormente, lidera seu resgate. Xi'er se casa com Dachun, e as cenas finais, em que o casal está sorridente, trabalhando no campo, sugerem a ideia de "viveram felizes para sempre". ${ }^{25}$

O filme foi realizado logo após a instalação da República Popular da China (1949), no início da década de 1950, quando Jiang Qing assumiu a chefia da censura do cinema, para usá-lo como ferramenta de propaganda do PCC. Proibiu também obras estrangeiras. Seu objetivo era que os filmes produzidos fossem dirigidos principalmente aos camponeses, mostrando o "passado como etapa vencida na construção de novos costumes". ${ }^{26}$ Esse enfoque no público de origem camponesa se devia ao fato de que o apoio dos camponeses foi essencial para a vitória comunista. O processo revolucionário chinês ocorreu em um país essencialmente agrário onde, em 1949, a agricultura era responsável por $90 \%$ da produção. Mao Zedong, desde 1927, valorizava o campesinato como agente revolucionário e, junto com a liderança do PCC, conseguiu mobilizá-lo para organizar, com sucesso, a guerra de guerrilha contra os japoneses durante a Segunda Guerra Mundial, e na guerra civil que veio a seguir (1946-49). A obra cinematográfica atende à fórmula pretendida, mostrando o fim do modelo 'feudal' e as mudanças trazidas pela revolução.

A versão na forma de balé, uma obra modelo da Revolução Cultural, foi apresentada em Beijing em 30 de abril de 1966, para a celebração do Dia de Maio. A revisão demorou dois anos para ser concluída e foi supervisionada diretamente por Jiang Qing. O enredo, apesar de se manter muito próximo da obra original, era mais conciso e os personagens, mais abstratos. Nessa versão, a ênfase foi dada à luta de classes, que pode ser evidenciada, por exemplo, quando Yang Bailao, pai de Xi'er, não comete suicídio, mas é espancado até a morte na luta contra seus opressores. Xi’er é tratada cruelmente, mas não é agredida sexualmente, e não tem nenhuma ligação romântica

\footnotetext{
${ }^{24}$ WITKE, R. Madame Mao. Op. cit., p. 361.

${ }^{25}$ HUS, S; BIN, W; RUNSHEN, Y. The White-Haired Girl. Film Script. Tradução de Pete Nestor e Tom Moran. MCLC Resource Center Publication. February, 2006. Disponível em: <http://u.osu.edu/mclc/online-series/white/>. Acessado em 19 dez. 2017.

${ }^{26}$ WITKE, R. Madame Mao. Op. cit., p. 219.
} 
com Wang Dachun. No final, Xi'er pega em armas e se junta ao Exército da $8^{\text {a }}$ Rota para continuar a revolução do proletariado.

As alterações mais evidentes em relação ao balé clássico foram marcantes também quanto ao figurino, música e gestualística. Os músicos foram instruídos por Jiang Qing a orientarem seus acordes no sentido do tema fundamental da história, que passou a ser a vingança. Embora também tenham sido usados instrumentos musicais ocidentais, eram os instrumentos chineses que expressavam as canções-tema e os momentos mais dramáticos, como nas cenas em que Xi'er se levanta contra a opressão ou quando ela recorda seus sofrimentos passados.

Outra diferença é o uso da voz humana em coro ou solo, que não aparecia no balé clássico. No revolucionário, foi utilizada para ressaltar as passagens dramáticas. $\mathrm{Na}$ cena em que o pai é morto pelo latifundiário, a canção de Xi'er ressalta sua ira e indignação.

Os movimentos de dança incorporaram elementos de ópera tradicional de Pequim e artes marciais; os punhos flexíveis do balé convencional foram substituídos por punhos firmes para indicar uma atitude de resistência heroica e revolta. E os figurinos não eram os tradicionais do balé clássico, pois os personagens usavam roupas evocando aquelas de camponeses e soldados.

\section{Alterações do enredo no balé em relação às demais obras}

Analisando a versão em forma de balé, verifica-se de início que a simplificação do enredo e dos personagens teve como propósito enfatizar o conceito de classe como a única categoria social dentro da qual as pessoas se organizavam. $\mathrm{O}$ discurso de classe substituiu conceitos éticos não politizados, princípios morais e os valores de entretenimento. Os laços familiares de esposa e mãe, os elementos sexuais e românticos foram eliminados. ${ }^{27}$

Algumas cenas ilustram as principais diferenças no enredo do balé em relação à ópera e ao filme. Essas se referem principalmente à protagonista, Xi'er.

\footnotetext{
${ }^{27}$ DI, B. Feminism in Revolutionary Model Ballets The White-Haired Girl and the Red Detachment of Women. p. 7. Disponível em: 〈http://thisiscommunism.org/pdf/final_model_theater-BaiDi.pdf.> Acessado em19 dez. 2017.
} 
A primeira alteração a ser analisada é a personalidade de Xi'er, apresentada na ópera e no filme, como uma camponesa ingênua, vulnerável e dependente, que precisava ser protegida e resgatada, por homens: seu pai, noivo, ou o comandante do Exército da $8^{\text {a }}$ Rota. No balé, Xi'er tornou-se numa heroína corajosa dotada de consciência de classe, que resistiu à opressão de Huang Shiren, sem medo. Ela não era mais uma donzela aflita esperando para ser resgatada por cavaleiros de armaduras reluzentes, mas uma protagonista que lutava por sua libertação e de sua classe, tornando-se, portanto, um modelo a ser seguido. ${ }^{28}$

Essa condição pode ser percebida, por exemplo, no episódio da morte de Yang Bailao. Na ópera, depois que Yang Bailao cometeu suicídio, o capataz de Huang Shiren vem para pegar Xi'er. Ela estava de luto, assustada, desamparada. Enquanto Dachun e outros aldeões estavam discutindo com o capataz, ela só chorava e procurava a proteção dos aldeões mais velhos, e até do falecido pai. Quando ela estava sendo levada, chorava, gritava e lutava com medo. A cena se desenrolava de forma semelhante no filme de 1950: quando Xi'er ouvia que seu pai a vendera a Huang Shiren, ela se jogava sobre o corpo morto de seu pai e, impotente, implorava aos tios para lhe dizer o que fazer e para salvá-la. ${ }^{29}$

No balé modelo, Xi'er tem resistência física e consciência política. Quando Huang Shiren e seus capangas forçaram Yang Bailao a assinar o contrato em que troca a servidão de Xi'er pela dívida da renda em grãos, Yang Bailao, em vez de se resignar e cometer suicídio, resistiu contra o opressor, e Xi'er se juntou a ele. Os dois lutaram heroicamente contra Huang Shiren e seu capataz. Quando seu pai foi espancado até a morte, Xi'er não chorou com medo ou amargura. Pelo contrário, ela denunciou o crime de Huang com profunda indignação e jurou se vingar. ${ }^{30}$

Também se pode perceber contraste semelhante na cena em que Xi'er é tratada cruelmente na casa de Huang. Na ópera original e no filme de 1950, Xi'er foi representada como amedrontada, impotente e submissa. Como serva de Huang e de sua mãe, Xi'er constantemente foi amaldiçoada e espancada. Sentindo pena de si mesma por

\footnotetext{
${ }^{28}$ ZHOU, Y. Holding up Half the Sky: Revisiting "Woman" Messages in Model Plays During China's Great Proletarian Cultural Revolution 1966-1976. p. 36. Disponível em: <http://citeseerx.ist.psu.edu/messages/ downloads excee ded.html>. Acessado em 19 dez. 2017.

${ }^{29}$ Idem, pp. 31-32.

${ }^{30}$ Idem, p. 32.
} 
ser maltratada o tempo todo, ela se resignou ao seu destino, engolindo as lágrimas e redobrando os cuidados para não irritar os donos da casa.

No balé, Xi'er, desde o momento em que foi levada para a casa de Huang, estava determinada a não aceitar o seu destino de se submeter a essa família. Ela continuou a resistir firmemente contra a crueldade do senhor das terras e de sua mãe, revidando seus maus-tratos e encarando os opressores de frente. Ao contrário das mulheres frágeis e vulneráveis na literatura e obras de arte tradicionais, Xi'er era dotada de força física, de tal maneira que conseguia derrubar os capangas durante as lutas. Ela não demonstrava medo, encarava os opressores com olhar penetrante, que significava ódio pela classe opressora e espírito de vingança. Ela, muitas vezes, provocou medo nos personagens negativos. Nessas cenas, apareciam os movimentos de artes marciais e punhos firmes, simbolizando resistência e revolta. ${ }^{31}$

Outra revisão significativa para a personagem Xi'er é que, no balé modelo, foram eliminados o estupro e a gravidez. Na ópera, após ser estuprada por Huang, a emoção mais forte que Xi'er sentiu foi vergonha. Tendo perdido sua virgindade, que na cultura tradicional chinesa representava a castidade da mulher solteira e a lealdade para com seu futuro marido, ela sentiu que perdeu a razão de viver. Xi'er decidiu cometer suicídio e mudou de ideia somente porque logo descobriu que estava grávida. Apesar das pessoas rirem dela e desprezá-la pela gravidez, ela escolheu "suportar a vergonha" e "engolir" suas lágrimas e seu orgulho, pela criança. Quando percebeu a família de Huang ocupada com os preparativos do casamento, sentiu-se aliviada imaginando que Huang iria se casar com ela. Expressou então sua disposição de sacrificar sua própria felicidade se casando apenas para o bem da criança. Essa versão apresentava uma imagem muito próxima da realidade de uma filha de camponês com as "velhas" ideias "feudais" de castidade, de destino e de mulher virtuosa. ${ }^{32}$

O filme de 1950 é considerado progressista quanto à personagem Xi'er que tinha uma maior consciência política e de classe, e reconhecia Huang como inimigo de classe, e não construía fantasias esperando que ele se casasse com ela depois de tê-la estuprado. A obra era praticamente uma história de amor entre dois jovens proletários, Xi'er e Dachun. Muitos close-ups foram usados para mostrar sua separação, seu emocionante reencontro. A última cena mostrava Xi'er, com seu cabelo preso, um sinal de status

\footnotetext{
${ }^{31}$ Idem, p. 33

${ }^{32}$ Idem, p. 35.
} 
conjugal para as mulheres no norte da China, feliz, trabalhando no campo juntamente com a mãe de Dachun.

Outras cenas demonstravam esse tema. Após Xi'er ser levada à força para a casa de Huang, ela enviara uma mensagem para a mãe de Dachun, onde deixava clara sua lealdade ao noivo "não importa o que aconteça, agora eu sou parte de sua família". Nas cenas de Xi'er sendo maltratada pela mãe de Huang, mesmo com todo o sofrimento, Xi'er ainda costurava sapatos ${ }^{33}$ para Dachun, uma indicação de que mesmo longe dele, nada poderia separá-los. O amor e a dependência de Xi'er em relação a Dachun foram representados para mostrar o contraste com a crueldade da classe opressora. Ela foi retratada como uma mulher frágil nas mãos do opressor, que estava à espera de ser salva por seu amado. ${ }^{34}$

As revisões para a personagem Xi'er e todo o enredo, feitas na versão cinematográfica de "A Moça do Cabelo Branco", enfatizavam seu amor fiel e leal por Dachun, um jovem que também era de uma família proletária. A liberação de Xi'er era representada como sendo finalmente realizada quando ela foi resgatada por Dachun e, feliz, casou-se com ele. Este tema coincide com a agenda oficial do partido Comunista Chinês para a libertação das mulheres como institucionalizado pela Lei do Casamento que foi aprovada como a primeira lei da Nova China em maio de 1950. Essa lei consagrava logo no seu artigo $1 .^{\circ}$, o princípio das proibições do sistema 'feudal' de casamento, de decisão arbitrária por terceiro ou uso de compulsão, da desigualdade de homem e mulher e do alheamento do interesse pelas crianças. Estabelecia o princípio de aplicação do sistema de casamento da Nova Democracia, baseado na escolha livre de parceiros nupciais, na monogamia, na igualdade de direitos entre homem e mulher e na proteção de direitos legais de mulheres e crianças que o Partido Comunista promoveu desde os Sovietes do Jiangxi. ${ }^{35}$

Enquanto o significado da lei do casamento para a libertação das mulheres chinesas é facilmente percebido, a mensagem subjacente ao discurso oficial de gênero requer uma análise mais aprofundada: a prioridade do novo governo era a reforma do

\footnotetext{
${ }^{33}$ Atividade clássica, por assim dizer, das camponesas em apoio aos membros do Exército Vermelho, muitos deles seus filhos e netos.

${ }^{34}$ ZHOU, Y. Holding up Half the Sky. Op. cit.

${ }^{35}$ CHUN, T. P. "Regimes matrimoniais de bens no ordenamento jurídico chinês após a publicação do Código Civil de 1931: sua relevância no ordenamento jurídico de Macau." Administração, n. ${ }^{\circ}$ 41, vol. XI, 1998, pp. 743-752. Disponível em: <www.safp.gov.mo/safppt/download/WCM_004167>. Acessado em 20 dez. 2017.
} 
casamento e da família, não a emancipação das mulheres, uma vez que a ideia era de que as mulheres chinesas conseguiriam sua emancipação através de um casamento heterossexual de sua livre escolha, dentro classe proletária. Da mesma forma, subjacente à representação das alegrias e tristezas da separação e reencontro entre Xi'er e Dachun, no filme, estava o entendimento de que para a mulher chinesa ficar livre de sofrimento e opressão era preciso encontrar o marido certo: um proletário que fosse amado e digno de confiança para salvá-la, vingá-la e libertá-la da classe opressora. Essa mensagem popular no discurso público da China na década de 1950 foi desafiada pela imagem de Xi'er na versão da obra modelo, em $1965 .{ }^{36}$

No balé, foi feita nova revisão: o estupro pelo senhorio, a gravidez e parto nas montanhas foram omitidos. Xi'er continuava sendo maltratada pelo senhorio e sua família, mas não era agredida sexualmente por Huang. Essas mudanças em relação à ópera original e à versão cinematográfica, no que se refere às ligações de Xi'er com Dachun e Huang Shiren, tinham por objetivo destacar o tema da luta de classes. Dachun não era descrito como o noivo de Xi'er da mesma maneira que nas versões anteriores. Em vez de amor romântico sexualizado, o balé representava o amor entre os dois como baseado em longos anos de dificuldades comuns e persistentes sob o regime opressivo do senhorio cruel, transformando Dachun em apenas mais um irmão de classe.

Pela eliminação de elementos sexuais e românticos, Xi'er não era mais julgada com base nas normas tradicionais restritivas para os papéis femininos de esposa, noiva, mãe e grávida. Ela estava acima da condição feminina convencional, onde as mulheres são consideradas o sexo frágil, que têm de aceitar passivamente seu destino e depender de homens, o sexo forte, para serem resgatadas. A decisão sobre sua vida e morte não pertencia mais a Dachun ou Huang Shiren. Ela era o agente ativo independente que lutava por sua própria sobrevivência e libertação. No final do balé ela pegava uma arma e se juntava às fileiras do Exército Vermelho, para lutar não só por sua libertação, mas a de toda a classe proletária. Essa cena representava sua transformação numa pessoa que exercia a liderança em prol do bem da coletividade, o que a tornava um modelo alternativo para as meninas chinesas que cresceram durante o período da Revolução Cultural. ${ }^{37}$

\footnotetext{
${ }^{36}$ ZHOU, Y. Holding up Half the Sky: Revisiting "Woman" Messages in Model Plays During China's Great Proletarian Cultural Revolution. 1966-1976, p. 36. Disponível em: <http://citeseerx.ist.psu.edu/messages/ downloads exceeded.html>. Acessado em 19 dez. 2017.

${ }^{37}$ Idem, p. 38.
} 


\section{Considerações finais}

Entre os maiores problemas enfrentados tanto por historiadores quanto por líderes revolucionários, está o de saber como as ideias se transformam em atitudes sociais. Na China, o teatro, mais conhecido pelos ocidentais como 'a ópera', foi um instrumento utilizado durante a Revolução Cultural. A ópera é a metáfora nacional por excelência dos chineses, sobretudo no período revolucionário, quando a relação entre a política e as artes foi enfatizada pelo pensamento marxista. $\mathrm{O}$ povo tanto recria melodramaticamente o passado, quanto honra e cultua seus patriarcas. ${ }^{38}$.

Da ópera original da década de 1940 ao filme da década de 1950, e depois, ao balé, nos anos 1960, constantes mudanças e revisões foram feitas no enredo de "A Moça do Cabelo Branco".

O Partido Comunista Chinês sempre demonstrou, mesmo antes de assumir o poder, uma preocupação em criar uma cultura proletária, que fosse um instrumento de propaganda para divulgar e consolidar sua ideologia.

Ainda em 1942, durante o Fórum de Yan'an, Mao Zedong afirmava que a arte era um componente da máquina da revolução, e estabelecia que era fundamental saber a quem os artistas serviam, e assegurar que levassem a nova cultura às regiões libertadas.

A nossa literatura e a nossa arte destinam-se, pois, em primeiro lugar, aos operários, que formam a classe que dirige a revolução; em segundo lugar, aos camponeses, o nosso aliado mais numeroso e mais resoluto na revolução; em terceiro lugar, aos operários e camponeses armados, por outras palavras, ao VIII Exército, ao Novo IV Exército e aos demais destacamentos armados do povo, forças principais da guerra revolucionária; em quarto lugar, às massas de trabalhadores e intelectuais da pequena burguesia urbana, que são também aliados nossos na revolução, susceptíveis de colaborar por muito tempo conosco. Essas quatro categorias representam a esmagadora maioria do povo chinês, são as grandes massas populares. ${ }^{39}$

Nesse espírito foi criada a ópera "A Moça do Cabelo Branco", adaptando uma estória do folclore, utilizando os elementos populares para mostrar uma realidade, ainda muito frequente de opressão dos camponeses pelos senhores da terra, dos princípios confucianos arraigados, principalmente no que se referia à condição feminina de obediência e submissão. No entanto, essa obra já apresentava, de forma clara, o conflito

\footnotetext{
${ }^{38}$ WITKE, R. Madame Mao. Op. cit., p. 327.

${ }^{39}$ MAO, Zedong. "Intervenções no colóquio de Ien-an sobre literatura e arte." In: Obras escolhidas de Mao Tsetung. Tomo III. Op. cit.
} 
de classes, o papel libertador do Exército Vermelho e a reforma agrária efetuada nas regiões controladas pelo Partido Comunista.

Após implantar a República Popular da China (1949), o Partido Comunista enfrentou constantes disputas políticas internas, que culminaram na Revolução Cultural lançada por Mao Zedong. Já na década de 1950, se iniciou o controle da produção cinematográfica, por orientação de Mao Zedong. Nessa época, no filme "A Moça do Cabelo Branco", além do conflito de classes, enfatizava-se a ideia de "um casamento feliz', em franca referência à legislação sobre o casamento aprovada em 1950, como foi visto acima, que garantia a livre escolha de parceiros e igualdade de direitos para homens e mulheres.

A versão do balé revolucionário simplificou o relacionamento de Xi'er com personagens masculinos: eram 'irmãos revolucionários' ou 'inimigos de classe'. Ela foi retratada como um símbolo de classe proletária, e destituída de suas características femininas, tornando-se igual a seus companheiros masculinos, na luta pelos direitos de classe. Entretanto Bai Di e Yuan Zhou argumentam que é a representação de uma situação idealizada de igualdade de gênero, como se lutando contra a opressão de classe as mulheres pudessem realmente alcançar essa igualdade em todas as áreas. Como Bai Di explica, somente quando Xi'er foi dissociada de seu corpo sexualizado e das funções de gênero derivadas de seu corpo (filha, esposa, mãe), ela pôde se tornar atuante para continuar a luta de classes. Foi a destituição de gênero da personagem que possibilitou Xi'er "tomar a arma para lutar por sua própria classe em vez de posar ao lado de Wang Dachun como uma esposa subordinada. ${ }^{40} \mathrm{O}$ contraste entre a imagem de Xi'er no balé, na da ópera e no filme revela o novo ideal de feminilidade e condição da mulher que foi promovida, segundo o objetivo de Jiang Qing, pelos projetos cultural e ideológico da Revolução Cultural. ${ }^{41}$

Nesta visão, o balé modelo representava uma situação do passado, onde camponeses e trabalhadores sofreram sob o regime 'feudal', enfrentaram corajosamente a revolução popular e finalmente alcançaram a libertação vitoriosa das classes opressoras, através do Partido Comunista.

\footnotetext{
${ }^{40}$ DI, B. Feminism in Revolutionary Model Ballets The White-Haired Girl and the Red Detachment of Women. Op. cit., p. 7.

${ }^{41}$ ZHOU, Y. Holding up Half the Sky. Op. cit., p. 38.
} 
Além do objetivo de retratar e disseminar a luta de classes, o balé revolucionário também serviu para enaltecer a figura do grande líder Mao Zedong, estimulando a lealdade ao Partido e ao seu presidente. No balé "A Moça do Cabelo Branco," na cena em que Xi"er era libertada pelo Exército Vermelho (Figura 1), ao fundo aparece um sol nascendo, numa clara alusão à representação do Presidente Mao em muitos cartazes durante a Revolução Cultural, em que seu rosto figurava em um círculo que irradiava os raios solares (Figura 2).



Figura 1

Fonte: https://www.pinterest.co.uk/pin/550142910701062665/ 


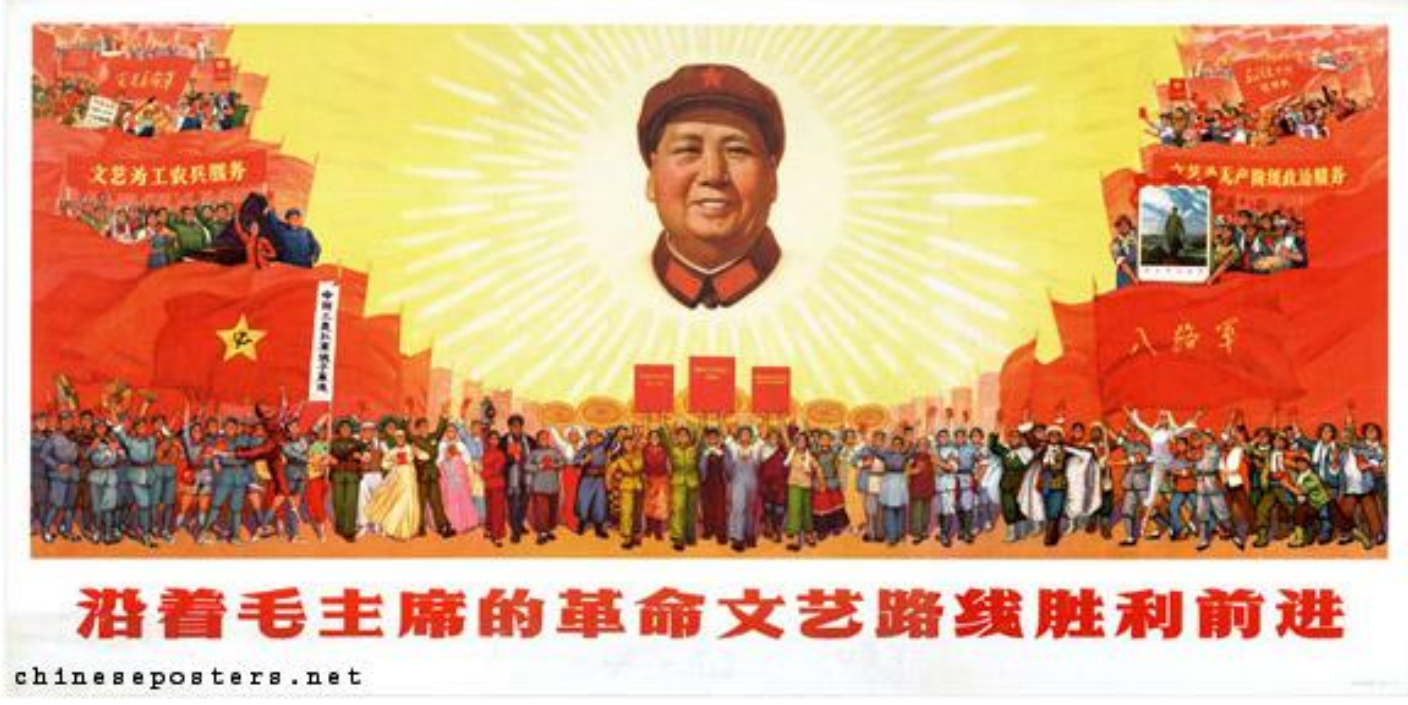

Figura 2

Fonte: chineseposters.net

A arte tem sido utilizada ao longo da história para apoiar causas políticas. Entretanto, durante a Revolução Cultural, as obras modelo tornaram-se verdadeiras peças de propaganda. A proibição de todo tipo de arte, com exceção das obras-modelo, deu aos responsáveis pela sua criação imenso poder e controle sobre os espectadores. A proibição da ópera tradicional demonstrou a influência de Jiang Qing e seus aliados, além de transmitir uma mensagem de que o Partido Comunista, na figura exclusiva de Mao Zedong, tinha o poder de controlar todos os aspectos da vida e da tradição do país. ${ }^{42}$

Embora ssociadas a um período de caos, em que muitos artistas e intelectuais foram perseguidos, torturados e mortos, as óperas-modelo retornaram aos palcos a partir da década de 1980 e se tornaram sucesso de público. Os balés-modelo "O Destacamento Feminino Vermelho" e "A Moça do Cabelo Branco" fazem parte do repertório do Balé de Xangai e do Balé Nacional da China. O atual sucesso dessas obras é creditado geralmente a um sentimento de nostalgia, uma vez que elas eram tão difundidas que passaram a fazer parte da vida dos chineses que viveram na época da Revolução Cultural (1966-1976). Mas esse não parece ser o único motivo.

\footnotetext{
${ }^{42}$ TERZUOLO, C. P. "Opera and Politics". Stanford Journal of East Asian Affairs. Vol. 9, $\mathrm{n}^{\circ} 1$, winter, 2009, p. Disponível em: $<$ https://web.stanford.edu/dept/CEAS/SJEAA/SJEAA\%20Vol.\%2009\%20Winter\%202009.pdf\#page=34 >. Acessado em 21 dez. 2017.
} 
Em outubro de 2014, Xi Jinping, presidente chinês desde 2013, proferiu um discurso sobre o papel da literatura e das artes na China, enfatizando que a literatura e arte socialistas são a literatura e a arte do povo, e devem persistir na orientação fundamental de servir ao povo e ao socialismo. Em consequência, em 2015, numa iniciativa do Ministério da Cultura da China, "A Moça do Cabelo Branco" voltou aos palcos, estreando em Yan'an, em comemoração aos 70 anos de sua primeira encenação. Esse fato, segundo comentário do professor Paul Clark, revela que a liderança do Partido considera essa obra como um "clássico para lembrar as glórias dos dias de Yan'an". ${ }^{43}$

Além desse discurso de Xi Jinping evocar o que foi proferido por Mao Zedong em Yan'an (1942), já referido neste artigo, outros pontos comuns podem ser notados nesse retorno de "A Moça do Cabelo Branco". Peng Liyuan, a segunda esposa de Xin Jinping, cantora de baladas, atuou no papel principal em A Moça do Cabelo Branco durante os anos 1980 e foi a diretora artística da produção de 2015, avaliando e orientando sua revisão, inclusive dando demonstrações durante os ensaios. ${ }^{44}$ Essas semelhanças entre Peng Liyuan e Jiang Qing não passam despercebidas, nem tão pouco as mudanças de conteúdo e apresentação da produção de 2015, com utilização de efeitos especiais, inclusive tecnologia 3D e som surround, aparentemente, para se adequar aos tempos presentes e continuar servindo ao povo e ao socialismo.

\section{Referências bibliográficas}

CHUN, T. P. Regimes matrimoniais de bens no ordenamento jurídico chinês após a publicação do Código Civil de 1931: sua relevância no ordenamento jurídico de Macau. Administração, ${ }^{\circ}$ 41, vol. XI, 1998, pp. 743-752. Disponível em: <www.safp.gov.mo/safppt/download/WCM_004167>. Acessado em 20 dez. 2017.

DABAT, Christine R. Mulheres no Movimento Revolucionário Chinês (1839 - 1949). Recife: Ed. Universitária da UFPE. 2006.

DI, B. Feminism in Revolutionary Model Ballets The White-Haired Girl and the Red Detachment of Women. Disponível em: <http://thisiscommunism.org/pdf/final_model_theaterBaiDi.pdf>. Acessado em 19 dez. 2017.

HUS, S; BIN, W; RUNSHEN, Y. The White-Haired Girl. Film Script. Tradução de Pete Nestor e Tom Moran. MCLC Resource Center Publication. February, 2006. Disponível em: <http://u.osu.edu/mclc/online-series/white/>. Acessado em 19 dez. 2017.

\footnotetext{
${ }^{43}$ BUCKLEY, C. "White Haired Girl, Opera created under Mao, returns to stage." The New York Times. 10 nov. 2015. Disponível em: <https://sinosphere.blogs.nytimes.com/2015/11/10/white-hairedgirl-opera-created-under-mao-returns-to-stage/>. Acesso em 07 abr. 2018.

44 :WANG, Y. "The White Haired Girl”: 70 years on. Beijing, 27 dez. 2015. Disponível em: <http://www.xinhuanet.com/english/china/2015-12/27/c_134955799.htm>. Acessado em 07 abr. 2018.
} 
JIA, Bo. Gender, Women's Liberation, and the Nation-State: A Study of the Chinese Opera The White-Haired Girl. Disponível em: 〈https://rucore.libraries.rutgers.edu/rutgers-lib/47419/>. Acessado em 19 dez. 2017.

KING, R. A shattered mirror: the literature of the Cultural Revolution. Disponível em: <https://open.library.ubc.ca/cIRcle/collections/ubctheses/831/items/ 1.0096575>. Acessado em 19 dez. 2017.

MAO, Zedong. "Intervenções no colóquio de Ien-an sobre literatura e arte." In: Obras escolhidas de Mao Tsetung. Tomo III. Disponível em: <https://www.marxists.org/portugues/mao/obras/index.htm > Acesso em 10 mai. 2017.

SCHMALTZ, M.. O moderno teatro chinês: desenvolvimento, percalços e pós-modernidade. Disponível em: https://www.researchgate.net/profile/Marcia_Schmaltz/publication/292130117 >. Acessado em 10 mai. 2017.

SPENCE, J. D. Em busca da China moderna: quatro séculos de história. Tradução Tomás R. B. e Pedro M. S. São Paulo: Companhia das Letras, 1995.

TERZUOLO, C. P. "Opera and Politics." Stanford Journal of East Asian Affairs. Vol. 9, n ${ }^{\circ}$, winter, 2009, p. Disponível em: $<$ https://web.stanford.edu/dept/CEAS/SJEAA/SJEAA\%20Vol.\%2009\%20Winter\%202009.pdf\# page $=34>$. Acesso em $21 \mathrm{dez} .2017$

The White haired-girl. Filme. 1950. Disponível em: <https://www.youtube.com/watch?v=vRQ9BjvqBNY>. Acessado em 20 dez. 2017.

WITKE, R. Madame Mao. Tradução de Donaldson Garschagen. Rio de Janeiro: Nova Fronteira, 1977.

ZHOU, Y. Holding up Half the Sky: Revisiting "Woman" Messages in Model Plays During China's Great Proletarian Cultural.Revolution 1966-1976. Disponível em: <http://citeseerx.ist.psu.edu/messages/ downloads excee ded.html>. Acessado em 19 dez. 2017. 